Int. J. Electrochem. Sci., 16 (2021) Article ID: 210246

International Journal of

ELECTROCHEMICAL

SCIENCE

www.electrochemsci.org

\title{
Electrochemical and Thermodynamic Properties of Diclofenac and Dibucaine Ions Across Water|1,6-dichlorohexane Interface
}

\author{
E. M. Almbrok ${ }^{1,2}$, N. A. Yusof ${ }^{1,3}$, J. Abdullah ${ }^{1}$ and R.M. Zawawi, ${ }^{1, *}$ \\ ${ }^{1}$ Department of Chemistry, Faculty of Science, University Putra Malaysia, 43400 UPM Serdang, \\ Selangor, \\ ${ }^{2}$ Department of Chemistry, Faculty of Education, Sebha University, 18758 Sebha, Libya \\ ${ }^{3}$ Institute of Advanced Technology, University Putra Malaysia, 43400 UPM Serdang, Selangor, \\ Malaysia \\ *E-mail: ruzniza@upm.edu.my
}

doi: $10.20964 / 2021.02 .26$

Received: 7 October 2020 / Accepted: 23 November 2020 / Published: 31 December 2020

\begin{abstract}
In this work, the electrochemical behaviour of diclofenac anion and dibucaine cation via a water|1,6dichlorohexane liquid | liquid interface system was characterised. Both ions have been undergone voltammetry of ion transfer across the liquid-liquid interface. Analytical parameters such as the formal transfer potential, standard Gibbs energy of transfer across the interface, and the partition coefficient for both drugs were determined. The partition coefficient is of great importance for the estimation of the lipophilicity' ions, which plays a role in its distribution in living organisms and its effect on biological media. Furthermore, the different performance characteristics of the cyclic voltammetry $(\mathrm{CV})$ technique were exploited to extract the values of the aqueous diffusion coefficients of both diclofenac and dibucaine, which were in a good agreement with the theoretically predicted values based on their molar mass, $4.18 \pm 0.05 \times 10^{-6} \mathrm{~cm}^{2} \mathrm{~s}^{-1}$ and $3.43 \pm 0.04 \times 10^{-6} \mathrm{~cm}^{2} \mathrm{~s}^{-1}$, respectively.
\end{abstract}

Keywords: Ion transfer - Diclofenac - Dibucaine - voltammetry - 1,6-dichlorohexane

\section{FULL TEXT}

(C) 2021 The Authors. Published by ESG (www.electrochemsci.org). This article is an open access article distributed under the terms and conditions of the Creative Commons Attribution license (http://creativecommons.org/licenses/by/4.0/). 